\title{
THM and reactive transport analysis of expansive clay barrier in radioactive waste isolation
}

\author{
L. do N. Guimarães ${ }^{1, *, \dagger}$, A. Gens ${ }^{2}$, M. Sánchez ${ }^{2}$ and S. Olivella ${ }^{2}$ \\ ${ }^{1}$ Departamento de Engenharia Civil, UFPE, Av. Acadêmico Hélio Ramos, s/n, \\ CEP: 50740-530, Recife-PE, Brazil \\ ${ }^{2}$ Geotechnical Engineering Department, Technical University of Catalunya, c/Jordi Girona 1-3, \\ Edificio D-2, 08034 Barcelona, Spain
}

\begin{abstract}
SUMMARY
A fully coupled formulation combining reactive transport and an existing thermo-hydro-mechanical (THM) code is briefly described. Special attention has been given to phenomena likely to be encountered in clay barriers used as part of containment systems of nuclear waste. The types of processes considered in the chemical formulation include hydrolysis, complex formation, oxidation/reduction reactions, acid/base reactions, precipitation/dissolution of minerals and cation exchange. Both kinetically controlled and equilibrium-controlled reactions have been incorporated. The formulation has been implemented in the finite element code CODE_BRIGHT. An application is presented concerning the performance of a large scale in situ heating test simulating high-level nuclear waste repository conditions. Copyright (c) 2006 John Wiley \& Sons, Ltd.
\end{abstract}

KEY WORDS: reactive transport problem; THM formulation; clay barrier; nuclear waste

\section{INTRODUCTION}

Compacted swelling clays are often envisaged as the main component of engineered barriers for radioactive waste disposal. These barriers are subjected to thermal loading due to the heat emitted by the waste and to hydration from water coming from the adjacent rock. As a consequence of these thermo-hydraulic phenomena, mechanical and chemical changes arise that, in turn, may affect all other aspects of behaviour. A correct understanding and prediction

\footnotetext{
*Correspondence to: L. do N. Guimarães, Departamento de Engenharia Civil, UFPE, Av. Acadêmico Hélio Ramos, s/n, CEP: 50740-530, Recife-PE, Brazil.

†E-mail: leonardo@ufpe.br

Contract/grant sponsor: ENRESA

Contract/grant sponsor: European Commission

Contract/grant sponsor: CNPq (Conselho Nacional de Desenvolvimento Cientíco e Tecnológico)

Contract/grant sponsor: Ministerio de Ciencia y Technología; contract/grant number: BTE2001-2227
}

Received 2 November 2005

Copyright (c) 2006 John Wiley \& Sons, Ltd.

Revised 2 November 2005

Accepted 15 November 2005 
of these barriers would require, therefore, the performance of fully coupled thermo-hydromechanical and chemical (THMC) numerical analyses.

Although there have been a number of coupled THM formulations proposed and the corresponding numerical codes have been available for some time (e.g. References [1-3]), coupled THMC formulations have lagged behind. Only recently, a number of proposals have been put forward in this field (e.g. References $[4,5]$ ). The research is now reaching a state that, through the incorporation into efficient computer codes, it is possible to perform coupled THMC numerical analyses to tackle engineering problems of a high level of complexity.

In this paper a fully coupled THMC formulation is briefly described that allows the performance of numerical analyses considering all four aspects of behaviour: thermal, hydraulic, mechanical and chemical and their interactions. The formulation takes into account the possibility that the material is partly saturated. The formulation is applied to the analysis of a real large-scale in situ heating test simulating nuclear repository conditions.

\section{DESCRIPTION OF THE THMC FORMULATION}

The main focus of the paper lies on the reactive transport problem. The THM component of the formulation adopt applied to clays $[6,7$ tions, constitutive equa of water (unknown: energy (unknown: ter example, the balance cquation for the mass of
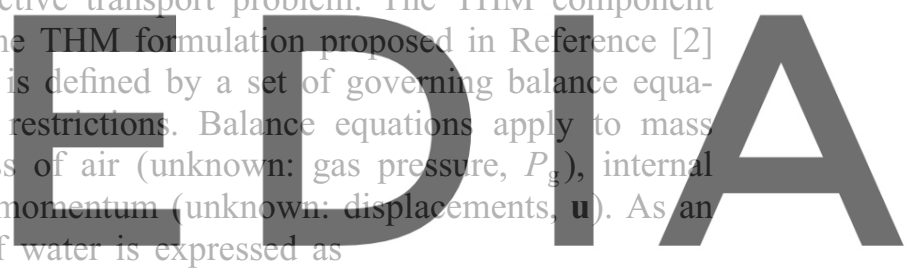

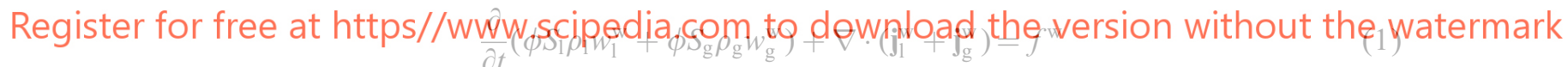

where $\phi$ is the porosity, $S_{1}$ and $S_{\mathrm{g}}$ the liquid and gas degree of saturation, $\rho_{1}$ and $\rho_{\mathrm{g}}$, the liquid and gas densities in $\mathrm{kg} / \mathrm{m}^{3}$ of phase, $w_{1}^{\mathrm{w}}$ the mass fraction of water in the liquid (close to one in dilute solutions) and $w_{\mathrm{g}}^{\mathrm{w}}$ the mass fraction of water vapour in the gas phase. The term $\phi S_{1} \rho_{1} w_{1}^{\mathrm{w}}$ is the water content in the liquid phase per unit volume and $\phi S_{\mathrm{g}} \rho_{\mathrm{g}} w_{\mathrm{g}}^{\mathrm{w}}$ the water content in the gas phase. $\mathbf{j}_{1}^{\mathrm{w}}$ and $\mathbf{j}_{\mathrm{g}}^{\mathrm{w}}$ are the mass flux of water in the liquid and gas phases, respectively. The term $f^{\mathrm{w}}$ may represent, in the context of this paper, the water production or loss associated with precipitation or dissolution of minerals. More details on the THM formulation are given in References [6,7].

To complete the THMC formulation, a number of additional chemical species are considered. The mass continuity of each chemical species is expressed by the reactive transport equation. In addition to the usual homogeneous reactions occurring in the liquid phase (aqueous complex formation, acid/base and oxidation/reduction), heterogeneous reactions that exchange matter between the liquid and the solid phase are also taken into account. The main heterogeneous reactions considered are dissolution/precipitation of minerals and cation exchange. In general the chemical processes are faster than the characteristic times of the THM problem, so it is assumed that chemical equilibrium prevails. Only some dissolution/precipitation processes are assumed to be kinetics-controlled. 
Let us consider the reactive transport of $N$ chemical species in a multiphase porous medium. The transport of every one of those species can be expressed as

$$
\frac{\partial}{\partial t}\left(\phi S_{1} \rho_{1} c_{i}\right)+\nabla \cdot \mathbf{j}_{i}=R_{i} \quad(i=1, \ldots, N)
$$

where $c_{i}$ is the concentration of species $i$ in $\mathrm{mol} / \mathrm{kg}$ of solution and $R_{i}$ is the total production rate of species $i$ due to chemical reactions, in $\mathrm{mol} / \mathrm{m}^{3} / \mathrm{s}$. $\mathbf{j}_{i}$ is the total flux of species $i$, in $\mathrm{mol} / \mathrm{m}^{2} / \mathrm{s}$. As in Reference [2], this flux is considered as the sum of advective and nonadvective fluxes. Advective flux is, in turn, the sum of the movement of the liquid phase with respect to the solid phase (governed by the generalized Darcy's law) and of the solid phase with respect to the reference configuration. The non-advective flux is the product of molecular diffusion and mechanical dispersion.

In order to make Equation (2) valid for all species, including those in the solid phase, it is convenient to express the total flux $\mathbf{j}_{i}$ as

$$
\mathbf{j}_{i}=\lambda_{i}\left(\rho_{1} C_{i} \mathbf{q}_{1}-\mathbf{D}_{1} \nabla c_{i}\right)+\phi S_{1} \rho_{1} c_{i} \mathbf{u}
$$

where $\lambda_{i}$ is the mobility of species $i . \lambda_{i}$ is 1 if the species is in the liquid phase and 0 if it is in the solid phase. $u$ is the solid phase velocity, $q_{1}$ is the Darcy's flux and $\mathbb{D}_{1}$ the hydrodynamic dispersion tensor (molecular diffusion plus mechanical dispersion).

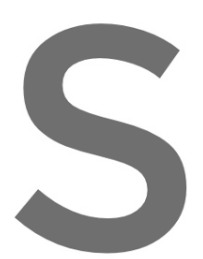

\section{If $N_{x}$ is the number} the number of indep classify the system between the two types
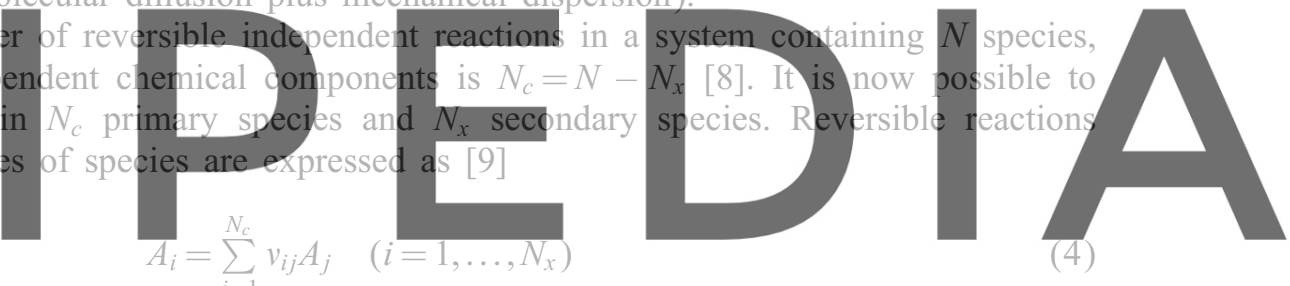

Register for free at https//www.scipedia.com to download the version without the watermark where $A_{j}$ and $A_{i}$ are the chemical formulas of the primary and secondary species, respectively, and $v_{i j}$ the number of moles of the primary species $j$ in a mol of the secondary species $i$. It should be noted that the classification of the species into primary and secondary ones is not unique [8].

Using the properties of the reversible reactions (4), it is possible to derive the basic transport equations $[8,9]$ :

$$
\begin{gathered}
\frac{\partial}{\partial t}\left(\phi S_{1} \rho_{1} U_{j}\right)+\nabla \cdot\left(\rho_{1} U a_{j} \mathbf{q}_{1}-\mathbf{D}_{1} \nabla U a_{j}+\phi S_{1} \rho_{1} U_{j} \dot{\mathbf{u}}\right)+\sum_{m=1}^{N_{m}} v_{j m} r_{m}=0 \quad\left(j=1, \ldots, N_{c}\right) \\
U_{j}=C_{j}+\sum_{i=1}^{N_{x}} v_{i j} X_{i} \quad\left(i=1, \ldots, N_{c}\right) \\
U a_{j}=\lambda_{j} C_{j}+\sum_{i=1}^{N_{x}} v_{i j} \lambda_{i} X_{i} \quad\left(i=1, \ldots, N_{c}\right)
\end{gathered}
$$

where $U_{j}$ is the total analytical concentration and $U a_{j}$ is the total aqueous concentration of the primary species $j . C_{j}$ and $X_{i}$ are the concentrations of the primary and secondary species, respectively. $\lambda_{j}$ and $\lambda_{i}$ are the mobilities of the primary and secondary species. $r_{m}$ is the rate of precipitation or dissolution of mineral $m$ under kinetics conditions and $N_{m}$ is the number of 
minerals in kinetics conditions. $v_{j m}$ is the number of moles of primary species $j$ in a mol of mineral $m$.

In the present formulation, the total analytical concentrations $U_{j}$ are the unknowns of the transport equation (5), and $U a_{j}$ and $r_{m}$ are considered non-linear functions of $U_{j}$. This type of unknown exhibits the interesting property of being independent of chemical equilibrium. Total analytical concentration changes in time are exclusively due to transport and kinetics reactions.

The link between the unknowns $U_{j}$ and the dependent variables $U a_{j}$ and $r_{m}$ is expressed by the geochemical model. In this formulation, an approach based on the direct minimization of Gibbs free energy is used [10]. To compute the concentrations of the species in equilibrium, a Newton-Raphson algorithm is applied to the direct minimization of Gibbs free energy and Lagrange multipliers are used to incorporate the restrictions of the problem. The implementation is well adapted to problems with highly dynamic appearance/disappearance of minerals as in the case presented in next section.

\section{EXAMPLE OF APPLICATION}

\subsection{The FEBEX in situ heating test}

A large-scale in situ heating test is being performed at the Grimsel Test Site, an underground

research laboratory located in the Swiss Alps. The rock in the site is mainly granite. The
test tries to reproduce the main features of the current Spanish concept for deep underground
disposal of high-level radioactive waste [11].
The test layout (Figure 1 ) consists in placing two heaters at the end of a drift of $2.28 \mathrm{~m}$
diameter and $70.4 \mathrm{~m}$ length specially bored for this purpese. The diameter and length of the
heaters ( 0.9 and $4.54 \mathrm{~m}$, respectively) corresponds to the actual dimensions of the canister

\section{Register for free at https//www.scipedia.com to download the version without the watermark}

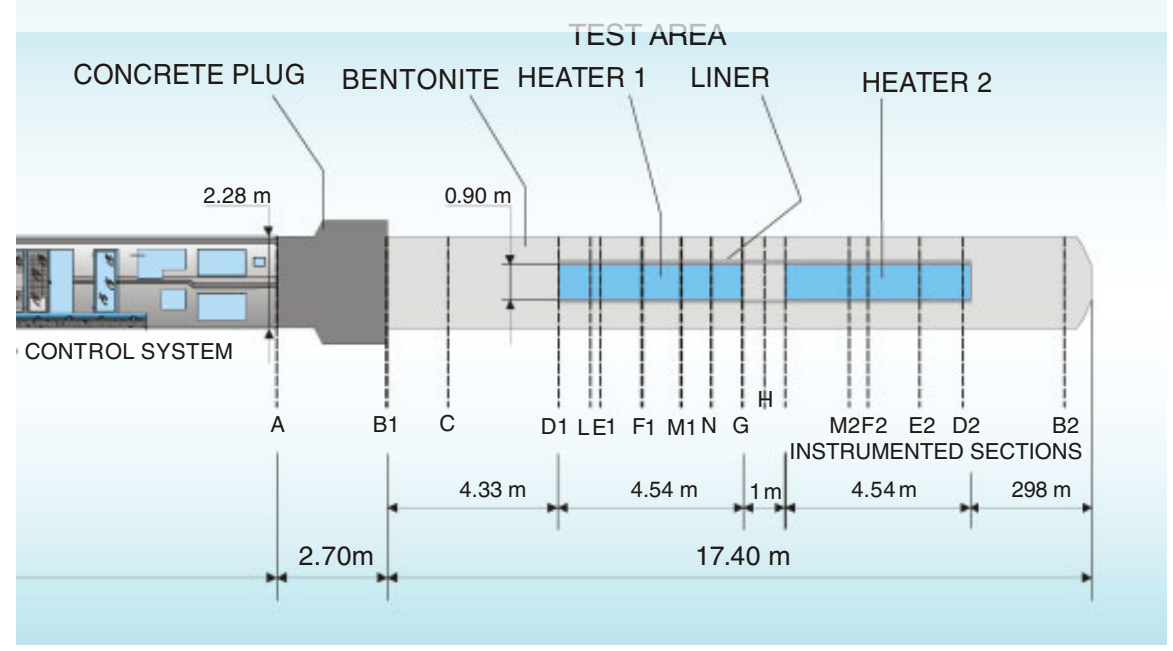

Figure 1. Lay out of the Febex in situ heating test. 
envisaged for radioactive waste storage. The heaters are placed in the axis of the drift at a $1 \mathrm{~m}$ distance from each other.

The space between the drift and the heaters is filled by blocks of compacted bentonite with a smectite content in the range of $88-96 \%$. The test is heavily instrumented with measurements of temperatures, relative humidity (equivalent to total suction), pore pressures, displacements, and stresses.

The test schedule involves switching on the heaters an applying increasing power until the temperature reaches a value of $100^{\circ} \mathrm{C}$ at some point in the bentonite. From that moment on, the power of the heaters is constantly adjusted in order to keep the maximum temperature in the bentonite barrier at the $100^{\circ} \mathrm{C}$ mark. The test was run in this way for 5 years until one of the heaters was switched off and dismantled. The experiment continues with the other heater without a planned finishing date. In the numerical simulation, a very fine one-dimensional finite element mesh was adopted that guarantees a Peclet number less than 2 for the transport problem, an important consideration when using a Galerkin-based finite element formulation.

\subsection{Features of analysis and chemical model}

Only a brief overview of the analysis characteristics will be given. More information is reported in References $[7,11]$. The numerical computations have been carried out using the fully coupled THMC version of CODE BRIGHT. Radial symmetry has been assumed resulting

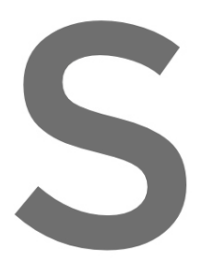

in a 1-D axisymmetr bentonite barrier and

After a short initia

temperature has been

dence with the test protocol. A

has been run up to 100 years to check and pre
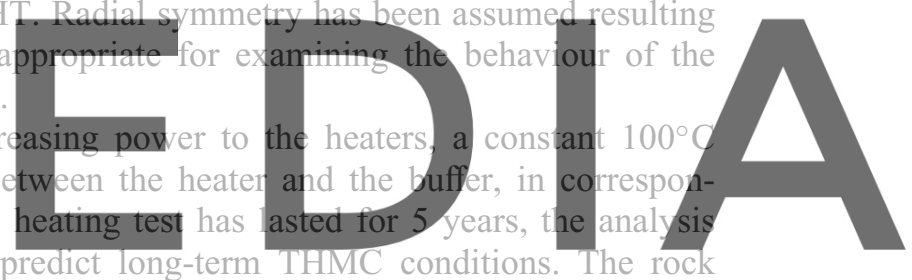

thermal, hydraulic and mechanical boundary conditions have been based on the results of the

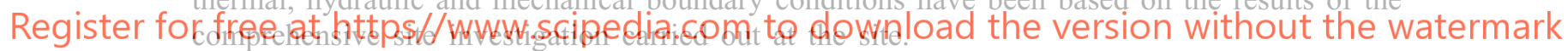

The initial conditions of the bentonite were as follows: dry density $1.7 \mathrm{~g} / \mathrm{cm}^{3}$ and water content 14.4\%. This results in an initial degree of saturation of 0.65 and an initial suction of $115 \mathrm{MPa}$. Both the bentonite (solid phase and interstitial water) and the hydration water were subjected to a full chemical characterization. The thermo-hydro-mechanical parameters were determined in an independent laboratory testing programme.

The selected primary species are $\mathrm{H}_{2} \mathrm{O}, \mathrm{Ca}^{2+}, \mathrm{K}^{+}, \mathrm{Na}^{+}, \mathrm{Mg}^{2+}, \mathrm{Cl}^{-}, \mathrm{SO}_{4}^{2-}, \mathrm{HCO}_{3}^{-}, \mathrm{H}^{+}$, $\mathrm{SiO}_{2}(\mathrm{aq}), \mathrm{NaX}$. They are all in the liquid phase except adsorbed sodium, $\mathrm{NaX}$, where $\mathrm{X}^{-}$ stands for the clay mineral. The secondary species, in equilibrium with the primary ones, are: $\mathrm{OH}^{-}, \mathrm{CO}_{3}^{2-}, \mathrm{CO}_{2}(\mathrm{aq}), \mathrm{CaCO}_{3}(\mathrm{aq}), \mathrm{CaHCO}_{3}^{+}, \mathrm{CaSO}_{4}(\mathrm{aq}), \mathrm{CaCl}^{+}, \mathrm{MgSO}_{4}(\mathrm{aq}), \mathrm{MgHCO}_{3}^{+}$, $\mathrm{MgCl}^{+}, \mathrm{NaHCO}_{3}(\mathrm{aq}), \mathrm{NaSO}_{4}^{-}, \mathrm{NaCl}(\mathrm{aq}), \mathrm{KSO}_{4}^{-}$and $\mathrm{HSiO}_{3}^{-}$.

A total cation exchange capacity, $\mathrm{CEC}=86.2 \mathrm{meq} / 100 \mathrm{~g}$ of solid has been used. The exchangeable cations are also secondary species and are controlled by the following reactions:

$$
\begin{aligned}
\mathrm{CaX}_{2} & =\mathrm{Ca}^{2+}+2 \mathrm{NaX}-2 \mathrm{Na}^{+} \\
\mathrm{MgX}_{2} & =\mathrm{Mg}^{2+}+2 \mathrm{NaX}-2 \mathrm{Na}^{+} \\
\mathrm{KX} & =\mathrm{K}^{+}+\mathrm{NaX}-\mathrm{Na}^{+}
\end{aligned}
$$


Finally, the phases in equilibrium with the solution of the liquid phase are:

$$
\begin{gathered}
\text { Calcite : } \mathrm{CaCO}_{3}(\mathrm{~s})=\mathrm{Ca}^{2+}+\mathrm{HCO}_{3}^{-}-\mathrm{H}^{+} \\
\text {Gypsum : } \mathrm{CaSO}_{4} \cdot 2 \mathrm{H}_{2} \mathrm{O}(\mathrm{s})=\mathrm{Ca}^{2+}+\mathrm{SO}_{4}^{2-}+2 \mathrm{H}_{2} \mathrm{O} \\
\text { Anhydrite }: \mathrm{CaSO}_{4}(\mathrm{~s})=\mathrm{Ca}^{2+}+\mathrm{SO}_{4}^{2-} \\
\text { Chalcedony : } \mathrm{SiO}_{2}(\mathrm{~s})=\mathrm{SiO}_{2}(\mathrm{aq}) \\
\text { Carbonic gas at } 10^{-3.5} \text { atm : } \mathrm{CO}_{2}(\mathrm{~g})=\mathrm{HCO}_{3}^{-}-\mathrm{H}_{2} \mathrm{O}+2 \mathrm{H}^{+}
\end{gathered}
$$

As a result of these assumptions, the number of unknowns per node was 13: one being the temperature, one the liquid pressure, one the displacement and the remaining 10 the primary chemical species (excluding water).

\subsection{Results of the THMC analysis}

Oniy a small selection of results will be shown here. They have been chosen to demonstrate the capabilities of the formulation and to point out some of the significant THMC features of the problem. THM results are given for three points of the buffer: one near the heater, one in the central part of the barrier and one closer to the rock (external buffer).

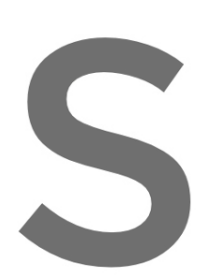

Figure 2 shows th ature is maintained
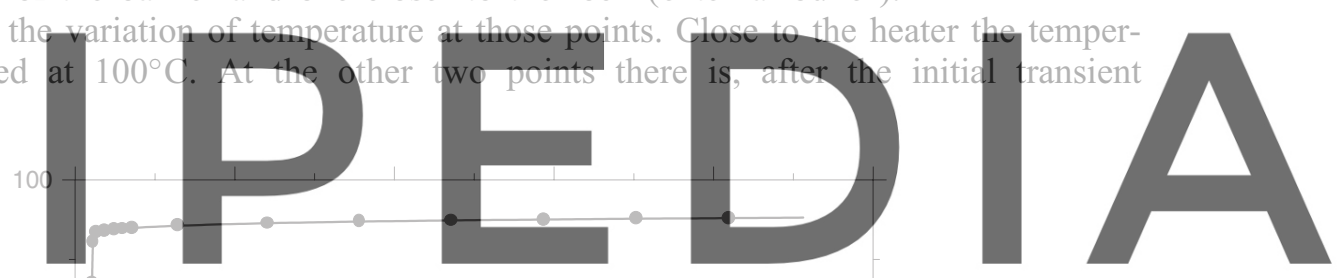

Register for free at https//Www.scipedia.com to download the version without the watermark

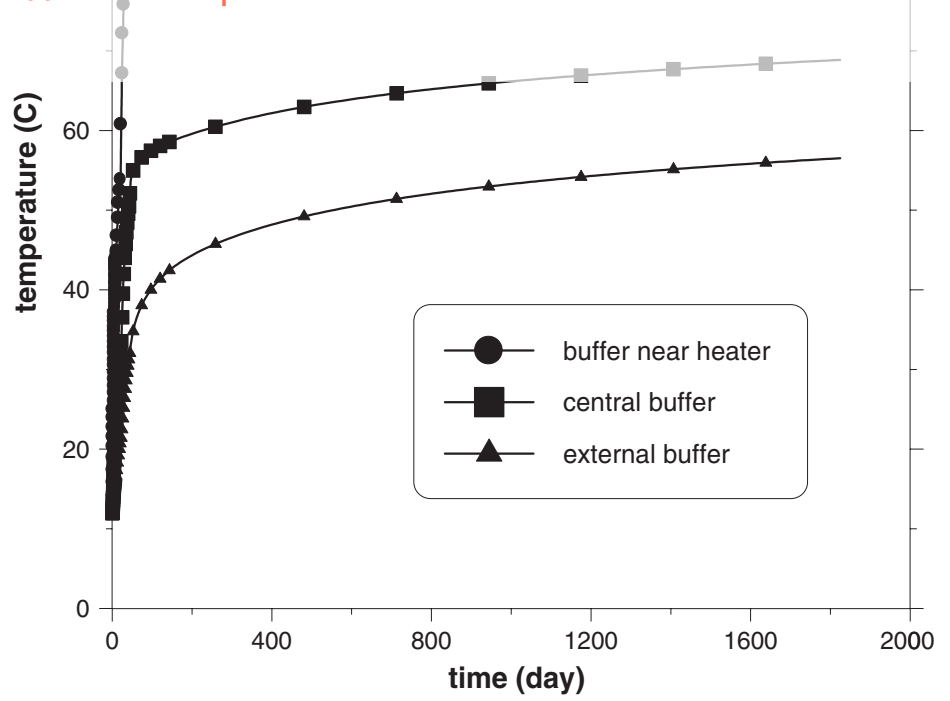

Figure 2. Variation of temperature with time ( 5 years) at three points of the bentonite barrier. 


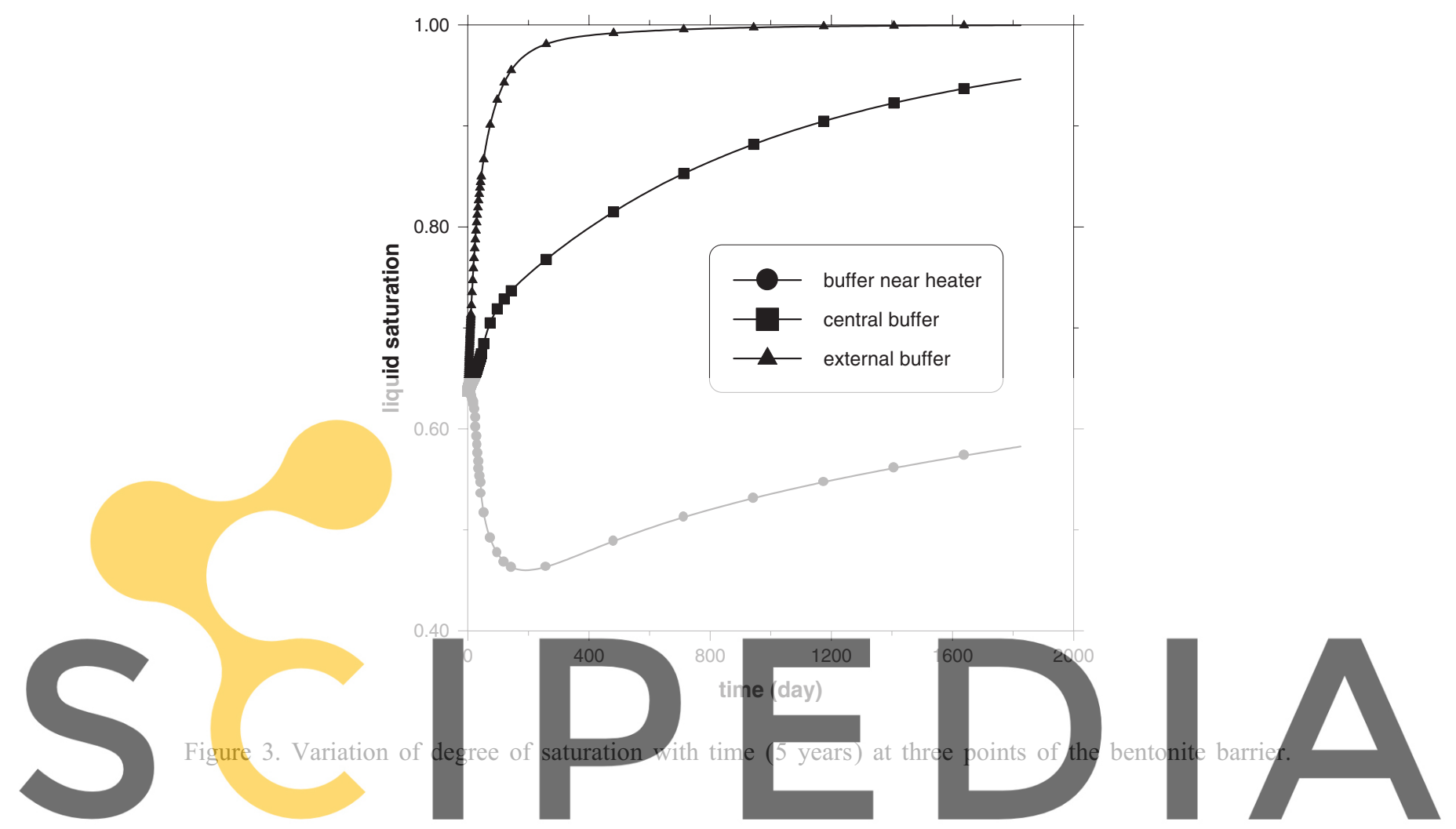

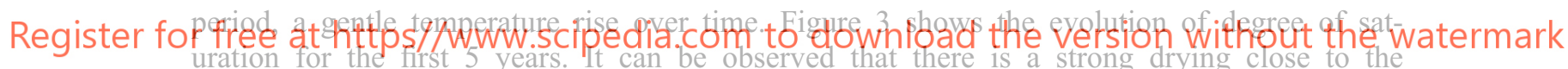

heater followed by a milder hydration afterwards. The part of the barrier close to the rock becomes quickly saturated, but the central part is still unsaturated after 5 years. In fact, the long-term calculations (Figure 4) indicate that more than 35 years would be required to achieve complete barrier saturation. More information on the THM results is given in Reference [7].

Figure 5 presents the ionic strength distribution in the buffer and in the rock at various times up to 100 years. Naturally the ionic strength in the granitic water is much lower than that of the bentonite water. It can be noted that the diffusion process is slow, after 100 years the solutes have only penetrated about $8 \mathrm{~m}$ in the rock. The ionic strength near the heater increases because of evaporation but the value reached is not very high.

The computed concentrations for some of the individual cations can be examined in Figures 6 and 7. The tendency is towards a dilution of the aqueous species in the barrier, specially, at shorter times, near the rock (Figure 6). Concentrations in the rock increase progressively due to diffusion. The exchangeable cations in the buffer clay do not vary much (Figure 7). There are some initial changes due to the impact of heating but the final cation content in the solid phase after 100 years is rather similar to the initial one. It should be stressed, however, that there is some uncertainty over the details of cation exchange processes at elevated temperature. 


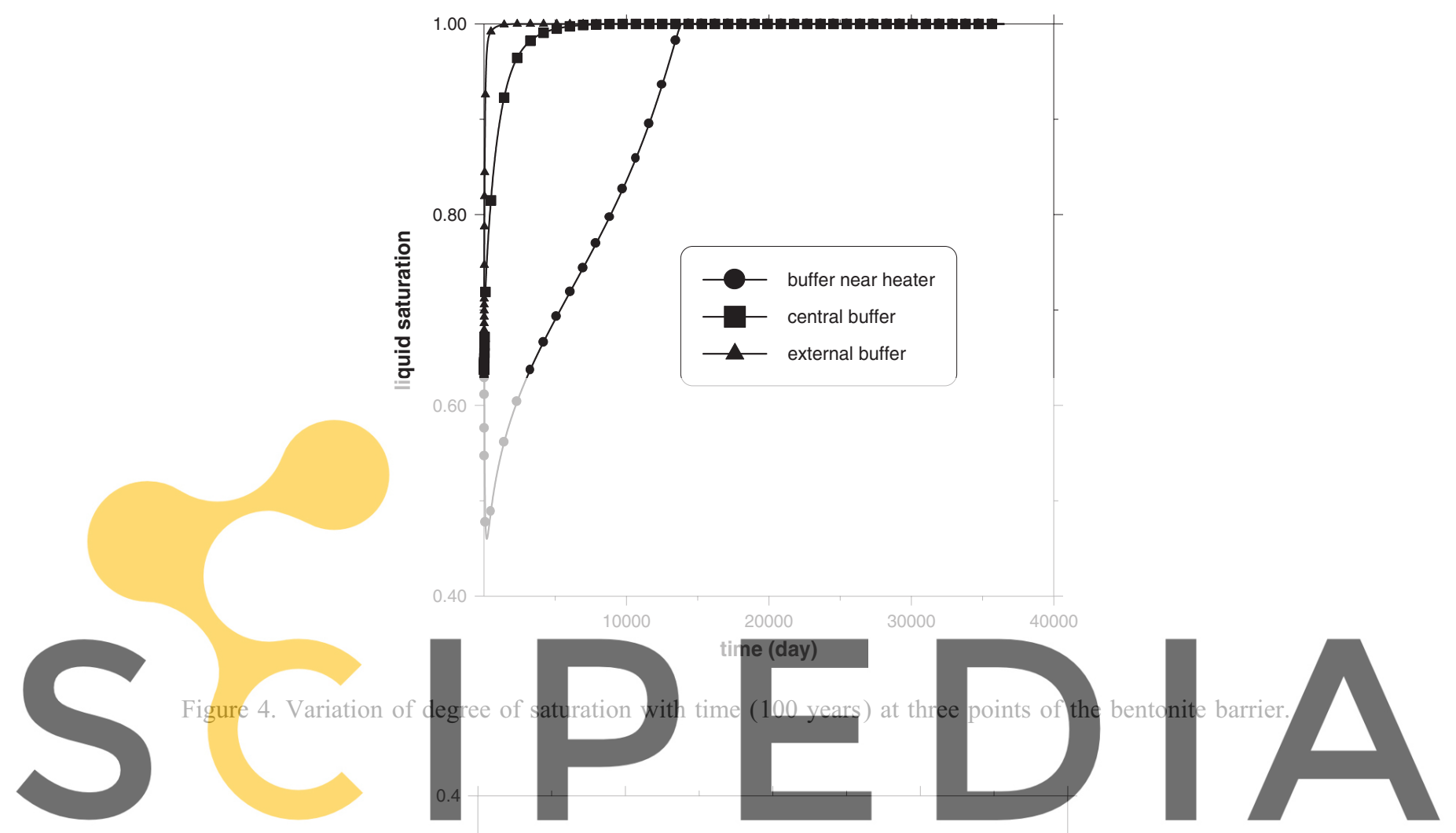

\section{Register for free at https//www.scipedia.com to download the version without the watermark}

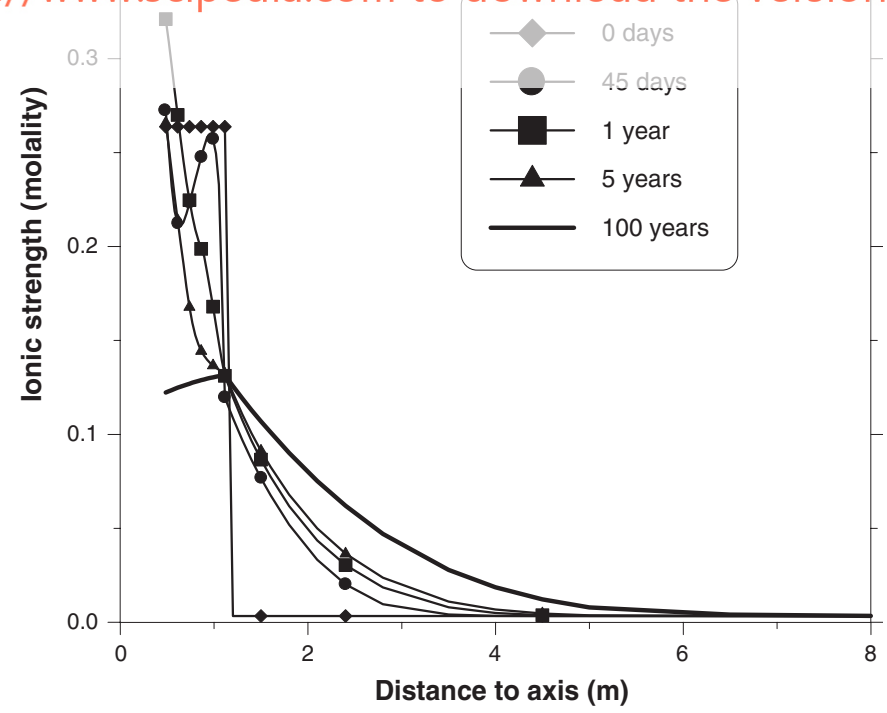

Figure 5. Distribution of ionic strength in the bentonite barrier and rock at various times. 

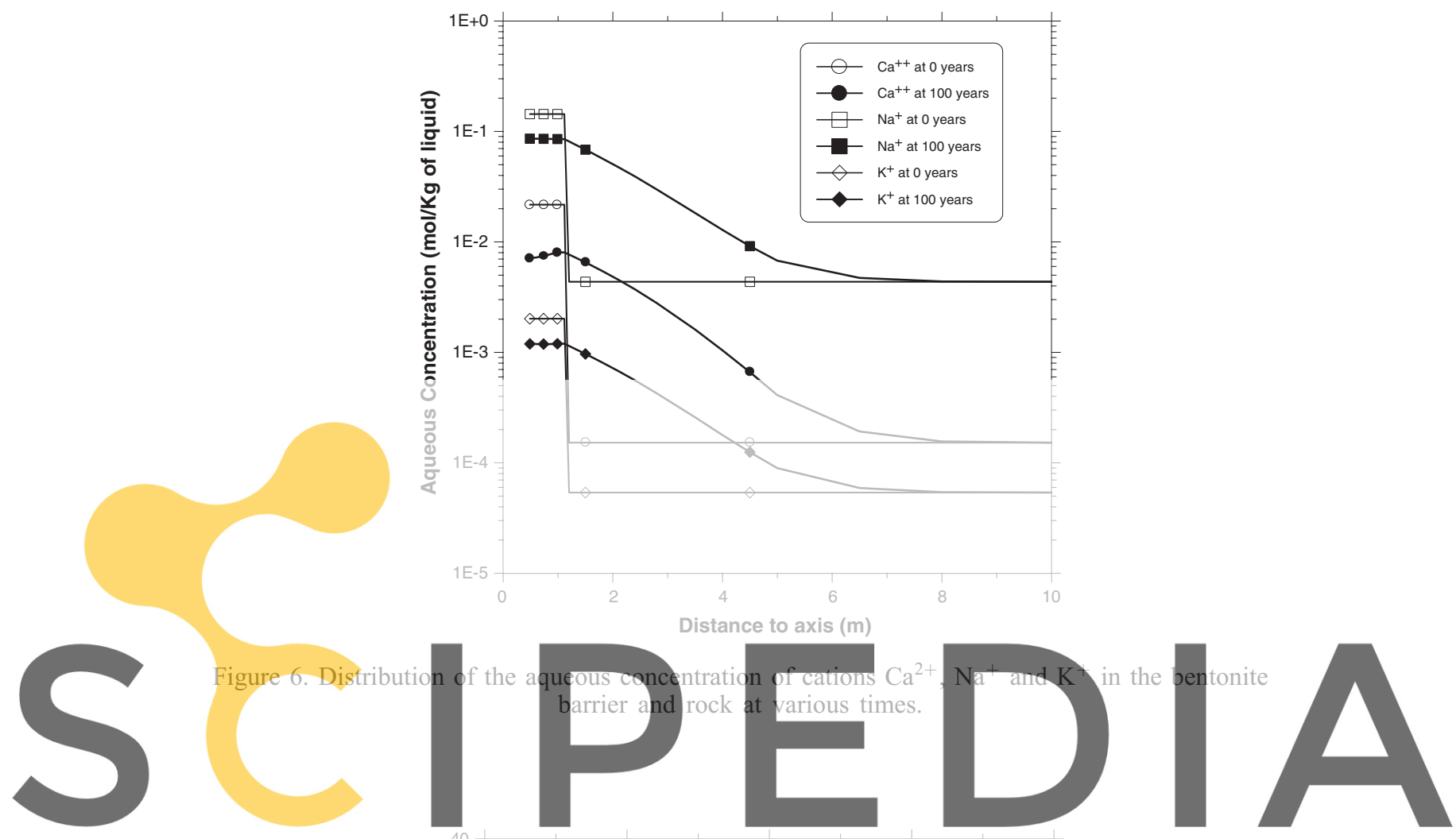

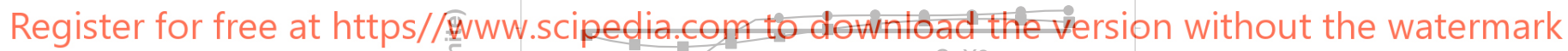

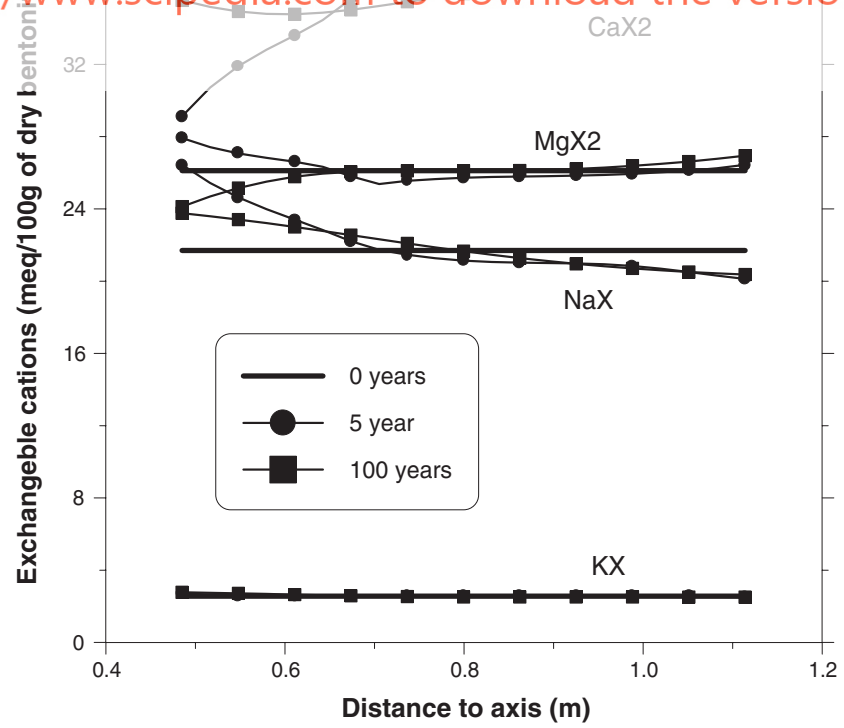

Figure 7. Distribution of exchangeable cations concentration in the bentonite barrier at various times. 


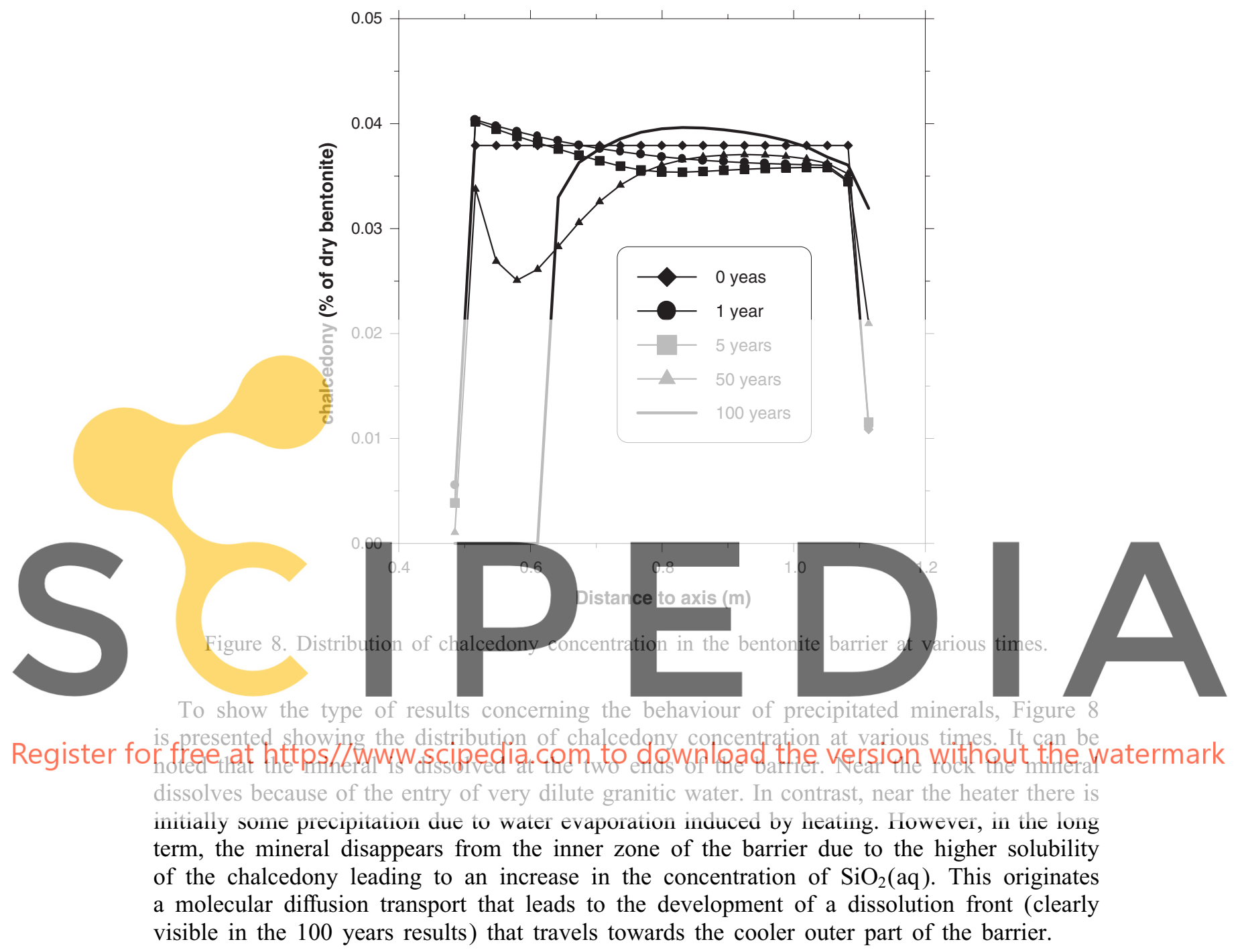

\section{CONCLUSIONS}

The paper has presented a very general and fully coupled THMC formulation that incorporates a significant number of THM processes and homogeneous and heterogeneous chemical reactions. The formulation has been incorporated into a computer code (CODE_BRIGHT) in order to perform numerical analysis. An example of application has been briefly described involving the simulation of a quite complex case: a large-scale in situ heating test that simulates the conditions of a repository for high-level nuclear waste. It can be concluded that, using the computational tool presented, the performance of coupled THMC analysis or real engineering problems is already a feasible proposition. 


\section{ACKNOWLEDGEMENTS}

This work has been supported by ENRESA and the European Commission. The authors are also grateful for the financial support given by $\mathrm{CNPq}$ (Conselho Nacional de Desenvolvimento Cientíco e Tecnológico) and the assistance of the Ministerio de Ciencia y Tecnología of Spain through research grant BTE2001-2227.

\section{REFERENCES}

1. Gawin D, Baggio P, Schhrefler BA. Coupled heat, water and gas flow in deformable porous media. International Journal for Numerical Methods in Fluids 1995; 20:967-987.

2. Olivella S, Carrera J, Gens A, Alonso EE. Nonisothermal multiphase flow of brine and gas through saline media. Transport in Porous Media 1994; 15:271-293.

3. Olivella S, Gens A, Carrera J, Alonso EE. Numerical formulation for a simulator (CODE_BRIGHT) for the coupled analysis of saline media. Engineering Computations 1995; 13:87-112.

4. Guimarães LN. Análisis multi-componente no isotermo en medio poroso deformable no saturado. Ph.D. Thesis, Geotechnical Engineering Department, Technical University of Catalunya, Spain, 2002.

5. Thomas HR, Cleall PJ, Hashm AA. Thermal/hydraulic/chemical/mechanical (THCM) behaviour of partly saturated soil. In Computer Methods and Advances on Geomechanics, Desai et al. (ed.), vol. 1. Balkema: Rotterdam, 2001; 743-748.

6. Gens A, García-Molina A, Alonso EE, Huertas F. Analysis of a full-scale in situ test simulating repository conditions. International Journal for Numerical and Analytical Methods in Geomechanics 1998; 22:515-548.

7. Gens A, Guimarães L do N, García-Molina A, Alonso EE. Factors controlling rock-clay buffer interaction in a radioactive waste repository. Engineering Geology 2002; 64:297-308.

8. Lichtner P. Continuum model for simultaneous chemical reactions and mass transport in hydrothermal systems. Geochimica et Cosmochimica Acta 1985; 49:779-800.

9. Steefel C, Lasaga A. A coupled model for transport of multiple chemical species and kinetic precipitation/ dissolution reactions with application to reactive flow in single phase hydrothermal systems. American Journal of Science 1994; 294:529-592.

10. Harvie C, Greenberg J, Weare J. A chemical equilibrium algorithm for highly non-ideal multiphase systems: free energy minimization. Geochimica et Cosmochimica Acta 1987; 51:1045-1057.

11. FEBEX. Full-scale engineered barriers experiment for a deep geological repository for high level radioactive waste in crystalline host rock. Final Report. Technical Publication 1/2000. ENRESA: Madrid, 2000. 